\title{
Have ozone effects on carbon sequestration been overestimated? A new biomass response function for wheat
}

\author{
H. Pleijel ${ }^{1}$, H. Danielsson ${ }^{2}$, D. Simpson ${ }^{3,4}$, and G. Mills ${ }^{5}$ \\ ${ }^{1}$ University of Gothenburg, Biological and Environmental Sciences, P.O. Box 461, 40530 Gothenburg, Sweden \\ ${ }^{2}$ Swedish Environmental Research Institute Inc., P.O. Box 53021, 40014 Gothenburg, Sweden \\ ${ }^{3}$ Norwegian Meteorological Institute, PB 43 Blindern, 0313 Oslo, Norway \\ ${ }^{4}$ Chalmers University of Technology, 41296 Gothenburg, Sweden \\ ${ }^{5}$ Centre for Ecology \& Hydrology, Environment Centre Wales, Deiniol Road, Bangor, Gwynedd, LL57 2UW, UK \\ Correspondence to: H. Pleijel (hakan.pleijel@bioenv.gu.se)
}

Received: 22 January 2014 - Published in Biogeosciences Discuss.: 8 April 2014

Revised: 19 June 2014 - Accepted: 18 July 2014 - Published: 27 August 2014

\begin{abstract}
Elevated levels of tropospheric ozone can significantly impair the growth of crops. The reduced removal of $\mathrm{CO}_{2}$ by plants leads to higher atmospheric concentrations of $\mathrm{CO}_{2}$, enhancing radiative forcing. Ozone effects on economic yield, e.g. the grain yield of wheat (Triticum aestivum L.), are currently used to model effects on radiative forcing. However, changes in grain yield do not necessarily reflect changes in total biomass. Based on an analysis of 22 ozone exposure experiments with field-grown wheat, we investigated whether the use of effects on grain yield as a proxy for effects on biomass under- or overestimates effects on biomass. First, we confirmed that effects on partitioning and biomass loss are both of significant importance for wheat yield loss. Then we derived ozone dose response functions for biomass loss and for harvest index (the proportion of above-ground biomass converted to grain) based on 12 experiments and recently developed ozone uptake modelling for wheat. Finally, we used a European-scale chemical transport model (EMEP MSC-West) to assess the effect of ozone on biomass $(-9 \%)$ and grain yield $(-14 \%)$ loss over Europe. Based on yield data per grid square, we estimated above-ground biomass losses due to ozone in 2000 in Europe, totalling 22.2 million tonnes. Incorrectly applying the grain yield response function to model effects on biomass instead of the biomass response function of this paper would have indicated total above-ground biomass losses totalling 38.1 million (i.e. overestimating effects by 15.9 million tonnes). A key conclusion from our study is that future assessments of ozone-induced loss of agroecosystem carbon
\end{abstract}

storage should use response functions for biomass, such as that provided in this paper, not grain yield, to avoid overestimation of the indirect radiative forcing from ozone effects on crop biomass accumulation.

\section{Introduction}

Tropospheric ozone is well known to significantly impair the growth of a wide variety of plants (Ainsworth et al., 2012), including forest trees, semi-natural vegetation and crops, e.g. ozone-sensitive species such as wheat (Feng and Kobayashi, 2009). Wheat is the most important crop in Europe and the fourth most important globally (http://faostat. fao.org/site/339/default.asp). The reduction in net photosynthesis and biomass accumulation caused by ozone is inevitably linked to a decreased uptake of $\mathrm{CO}_{2}$ and thus storage of organic carbon, leading to an enhanced radiative forcing (Ainsworth et al., 2012). Assessments of this indirect contribution to global warming by elevated tropospheric ozone have incorrectly assumed that the grain yield of wheat would represent an estimate of the biomass effect of an ozone-sensitive crop represented by wheat (Sitch et al., 2007; Collins et al., 2010). The grain yield was transformed into net photosynthesis by assuming that the relative effect of ozone on net photosynthesis is identical to the relative effect on grain yield representing "plant production". This neglects the fact that a large fraction of the ozone effect on economic yield, e.g. grain yield in wheat, depends 
on altered partitioning of biomass between reproductive and non-reproductive parts of the plant (Pleijel et al., 1995; Leisner and Ainsworth, 2012); the implications of excluding this effect are discussed and an alternative function is proposed for use in modelling indirect radiative climate forcing.

Many crops (including wheat) are annuals, flowering only once. Their life cycle is characterised by an initial nonreproductive stage of biomass accumulation, which is followed by a reproductive phase including flowering and grainfilling (Evans, 1993). When the plant has entered the reproductive stage it becomes prone to senescence, which can be enhanced by stresses such as elevated ozone (Grandjean and Fuhrer, 1989; Pleijel et al., 1998). The shortened reproductive phase results in a smaller biomass accumulation during this phase compared to the non-reproductive phase, leading to a less complete redistribution of carbohydrates from the photosynthesis of non-reproductive plant parts to grain (Pleijel et al., 1997).

Formally the relationship between grain yield, biomass partitioning between reproductive and non-reproductive parts, and biomass accumulation can be represented by

$Y_{\mathrm{G}}=H_{\mathrm{I}} B_{\mathrm{A}}$,

where $Y_{\mathrm{G}}$ is grain yield, $H_{\mathrm{I}}$ is the harvest index (the fraction of above-ground biomass forming grain; Evans, 1993) and $B_{\mathrm{A}}$ is the above-ground biomass at harvest. $H_{\mathrm{I}}$ represents the efficiency with which above-ground biomass of the crop is converted to seeds. We can denote $Y_{\mathrm{G}}$ in a situation with elevated ozone (or exposure to any other environmental factor) as $f_{1} Y_{\text {Gref }}$, where $Y_{\text {Gref }}$ is the grain yield in a reference situation, e.g. a control treatment in an experiment, and $f_{1}$ is a factor representing the degree of influence (e.g. by ozone) on $Y_{\mathrm{G}}$, positive if $f_{1}>1$ and negative if $\mathrm{f}_{1}<1$. It follows from Eq. (1) that $f_{1}$ can be expressed as a function of the effects $f_{2}$ and $f_{3}$ on $H_{\mathrm{I}}$ and $B_{\mathrm{A}}$, respectively, by setting

$f_{1} Y_{\text {Gref }}=f_{2} H_{\text {Iref }} f_{3} B_{\text {Aref }}$.

Here, $H_{\text {Iref }}$ and $B_{\text {Aref }}$ are the harvest index and above-ground biomass in the control treatment or reference situation. When the values of grain yield, harvest index and above-ground biomass are known for the reference treatment $\left(Y_{\text {Gref }}, H_{\text {Iref }}\right.$, $\left.B_{\text {Aref }}\right)$ and for a treatment with for example higher ozone $\left(Y_{\mathrm{G}}, H_{\mathrm{I}}, B_{\mathrm{A}}\right), f_{1}, f_{2}$ and $f_{3}$ can be calculated as $B_{\mathrm{A}} / B_{\text {Aref }}$, $H_{\mathrm{I}} / H_{\text {Iref }}$ and $Y_{\mathrm{G}} / Y_{\text {Gref }}$, respectively. If $f_{2}$ is much closer to unity than $f_{3}$, it follows that biomass effects are dominating the effects on $Y_{\mathrm{G}}$, but if $f_{2}$ differs substantially from unity, effects on partitioning are also important.

The aim of this investigation was to elucidate the role of biomass partitioning for ozone effects in crops to understand the magnitude of the error caused by using grain yield loss as a proxy for biomass yield loss (used to estimate reduction in net photosynthesis) from ozone in investigations of the indirect radiative forcing from ground-level ozone. More specifically, we (1) quantify the relative contribution of biomass accumulation and biomass partitioning for the ozone effects on wheat grain yield, (2) derive dose-response functions for effects of ozone on biomass accumulation and harvest index in wheat, and (3) assess the magnitude and geographical distribution of the effect of ozone on biomass loss and grain yield loss in wheat over Europe using the EMEP MSC-West model (Simpson et al., 2012). Our hypothesis was that the ozone effect on wheat grain yield is significantly larger than the effect on biomass accumulation, and that studies which ignored this difference have likely substantially overestimated the indirect radiative forcing from ozone caused by effects on crop growth.

\section{Materials and methods}

Data on wheat $Y_{\mathrm{G}}, B_{\mathrm{A}}$ and $H_{\mathrm{I}}$ from experiments using field-grown wheat were extracted from peer-reviewed literature, using Web of Science (http://thomsonreuters.com/ thomson-reuters-web-of-science/, last access: 20 February 2013), for 22 experiments, representing 8 countries and 3 continents (Table 1).

For Figs. 1 and 2, the charcoal-filtered (CF) air treatment of each experiment was used as a reference to which treatments with non-filtered air or elevated ozone were compared. This was conducted on a relative effect scale by dividing the value of the three biological variables for a certain treatment with that of the CF reference treatment in each experiment. In Fig. 1 the effect on grain yield is plotted against the effect on total above-ground biomass, whereas in Fig. 2 the effect on grain yield is plotted against the effect on harvest index. The deviation of the regression line from a hypothetical $1: 1$ relationship was tested according to Underwood (1997). In this part of the study only the 19 experiments containing a $\mathrm{CF}$ treatment, being used as the reference, were included.

Dose-response functions (Figs. 3 and 4) were derived for the relative effect of ozone on above-ground biomass and harvest index, respectively, based on the Phytotoxic Ozone Dose (representing the stomatal ozone uptake by the sunlit leaves) above a threshold of $6 \mathrm{nmol} \mathrm{m}^{-2} \mathrm{~s}^{-1}$ based on hourly values ( $\mathrm{POD}_{6}$ ) (Mills et al., 2011b). Stomatal conductance was estimated from air humidity (vapour pressure deficit), temperature, solar radiation and the influence of phenology (LRTAP Convention, 2010; Grünhage et al., 2012). Effects were related to the effect estimated at zero $\mathrm{POD}_{6}$ for each experiment. At zero $\mathrm{POD}_{6}$ exposure, the biological variables were set to take the value of 1 on a relative scale, in other words it was assumed that there was no ozone effect associated with zero $\mathrm{POD}_{6}$ in each experiment. The details of the methodology for the calculations, including the regression method for defining relative yields for individual experiments, have been described earlier (Pleijel et al., 2007; Mills et al., 2011b; Grünhage et al., 2012), including tests of the model with respect to observed data. The full model calibration, including all details, is presented in the Mapping Manual of the Convention on Long-Range Transboundary 


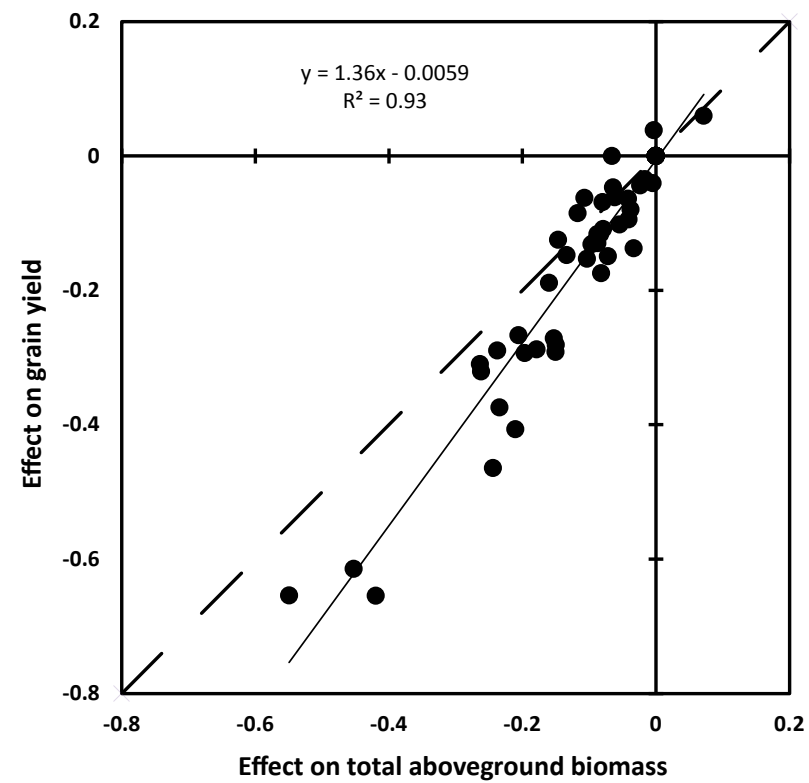

Figure 1. Relative effects of ozone on grain yield vs. above-ground biomass based on 19 experiments with field-grown wheat from 8 countries. Effects are relative to the treatment with charcoal-filtered air, i.e. an ozone concentration near zero. The broken line represents a hypothetical $1: 1$ relationship.

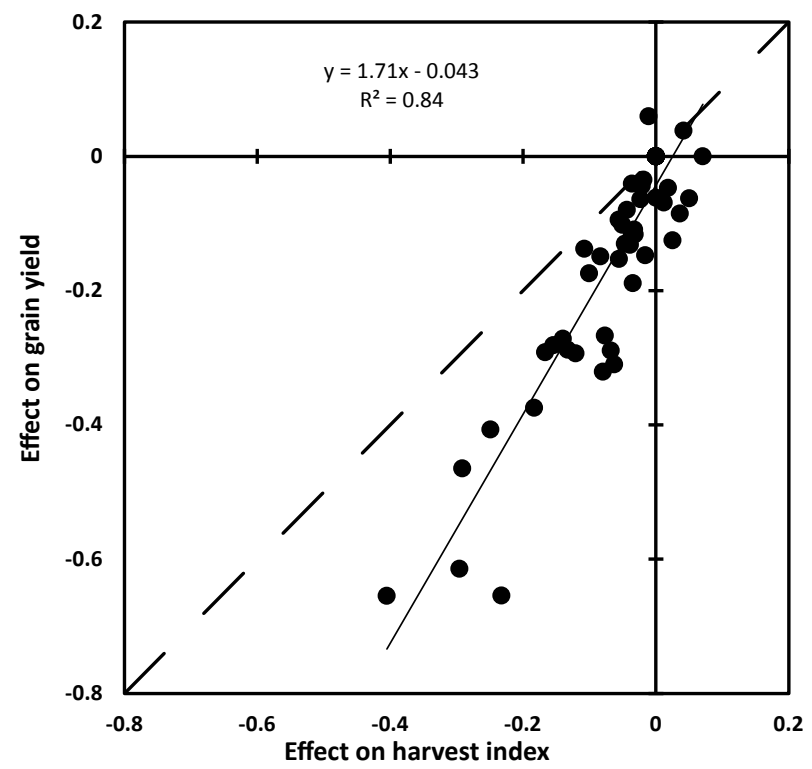

Figure 2. Relative effects of ozone on grain yield vs. harvest index based on 19 experiments with field-grown wheat from 8 countries. Effects are relative to the treatment with charcoal-filtered air, i.e. an ozone concentration near zero. The broken line represents a hypothetical $1: 1$ relationship.

Air Pollution (LRTAP Convention, 2010). A sub-set of 12 (performed in Sweden, Finland and Belgium) out of the 13 experiments, from which the response function for ozone effects on grain yield in wheat was derived (Mills et al.,
Table 1. References used to extract data for Figs. 1-2 and Figs. 34 as well as the number of experiments used deriving from each reference.

\begin{tabular}{lcc}
\hline Reference & Figures 1-2 & Figures 3-4 \\
\hline Fuhrer et al. (1989) & 3 & \\
Fuhrer et al. (1992) & 2 & 1 \\
Gelang et al. (2000) & 1 & \\
Mortensen and Engvild (1995) & 1 & \\
Mulchi et al. (1995) & 1 & \\
Mulholland et al. (1998) & 1 & 3 \\
Ojanperä et al. (1998) & 1 & 3 \\
Piikki et al. (2008) & 3 & 2 \\
Pleijel et al. (1991) & 2 & 1 \\
Pleijel et al. (1998) & & 1 \\
Pleijel et al. (2000) & & \\
Pleijel et al. (2006) & 1 & \\
Rai et al. (2007) & 1 & \\
Slaughter et al. (1989) & 2 & \\
\hline
\end{tabular}

2011b; Grünhage et al., 2012), were used to derive functions for harvest index and above-ground biomass, as these data were lacking for one of the 13 experiments. The experiments included in the dose-response relationships have been described in the scientific literature (Table 1). For the results presented in Figs. 3 and 4, only those experiments for which hourly values were available regarding ozone concentration, temperature, relative humidity or vapour pressure deficit, and solar radiation for the growing season were included. The calculation of the $\mathrm{POD}_{6}$ exposure index requires this information.

Percentage yield loss (response function in Mills et al., 2011b) and biomass loss (response function in Fig. 3 of the present paper) were calculated for the $\mathrm{EU} 27+\mathrm{CH}+\mathrm{NO}$ countries in Figs. 5 and 6 using $50 \times 50 \mathrm{~km}$ (approximately) grid square $\mathrm{POD}_{6}$ values determined for the year 2000 using the EMEP MSC-W Eulerian model, version rv 3.7 (Simpson et al., 2012) that simulated the emissions, transport, transformation and removal of pollutants, including calculation of ozone fluxes using the Deposition of Ozone for Stomatal Exchange $\left(\mathrm{DO}_{3} \mathrm{SE}\right)$ model (Emberson et al., 2001; Simpson et al., 2007; Tuovinen et al., 2007). Impacts of ozone on total above ground biomass were calculated based on the total yield per $50 \times 50 \mathrm{~km}$ grid square (see Mills and Harmens, 2011 for method) using the following relationship, derived from the published experimental data included in the current analysis:

$B_{\mathrm{A}}=\left(1.371 Y_{\mathrm{G}}\right)+4.705$

Units are tonnes per hectare for biomass and grain yield. Total effects for Europe (in million tonnes) were calculated by summing effects on biomass or grain yield in every grid square where wheat is grown. Figure 6 shows effects for the 


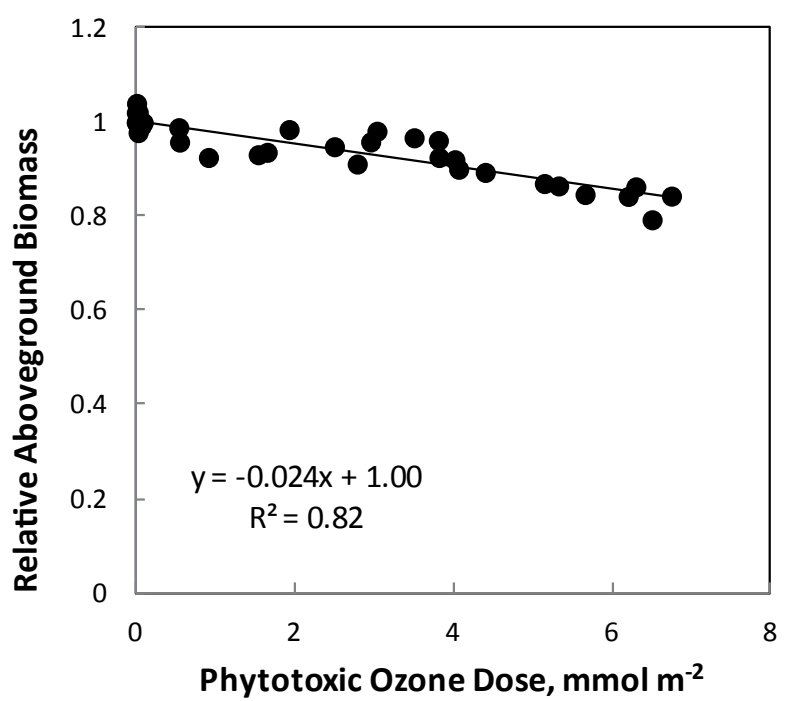

Figure 3. Relative above-ground biomass vs. Phytotoxic Ozone Dose above a threshold of $6 \mathrm{nmol} \mathrm{m}^{-2} \mathrm{~s}^{-1}\left(\mathrm{POD}_{6}\right)$ based on 12 experiments from 3 countries (Belgium, Finland, Sweden). The relative scale is based on the assumption that there is no ozone effect on above-ground biomass at zero $\mathrm{POD}_{6}$ in each experiment.

$50 \times 50 \mathrm{~km}$ grid squares where total wheat yield exceeded 6000 tonnes.

\section{Results}

\subsection{Effect of ozone on $Y_{G}$ in relation to effects on $B_{A}$ and $H_{I}$}

From Fig. 1 it can be inferred that effects of ozone (in relation to clean air and with respect to ozone using charcoal-filtered air) on wheat $Y_{\mathrm{G}}$ are strongly correlated $\left(R^{2}=0.93\right)$ to the effects on $B_{\mathrm{A}}$. Effects on $Y_{\mathrm{G}}$ are, however, larger than on $B_{\mathrm{A}}$, as shown by the strong and statistically significant deviation of the regression line from the hypothetical $1: 1$ relationship $(p<0.001)$ which represents a situation where $Y_{\mathrm{G}}$ effects would be entirely explained by effects in $B_{\mathrm{A}}$. Correspondingly, Fig. 2 shows that effects on $Y_{\mathrm{G}}$ are correlated to effects on $H_{\mathrm{I}}\left(R^{2}=0.84\right)$, but with an even larger deviation from the $1: 1$ line than in Fig. 1. This indicates that the ozone effects on $H_{\mathrm{I}}$ are of significant, but smaller, importance than effects on $B_{\mathrm{A}}$ for ozone effects on $Y_{\mathrm{G}}$. Furthermore, in Fig. 2 the deviation of the regression line from the hypothetical $1: 1$ relationship was strongly significant $(p<0.001)$. Obviously, the effects of ozone on both $B_{\mathrm{A}}$ and $H_{\mathrm{I}}$ are important for the effect on grain yield. Over the range of all ozone treatments, the average value of $f_{1}$ in Eq. (2) was 0.807 , while $f_{2}$ was 0.924 and $f_{3}$ was 0.865 .

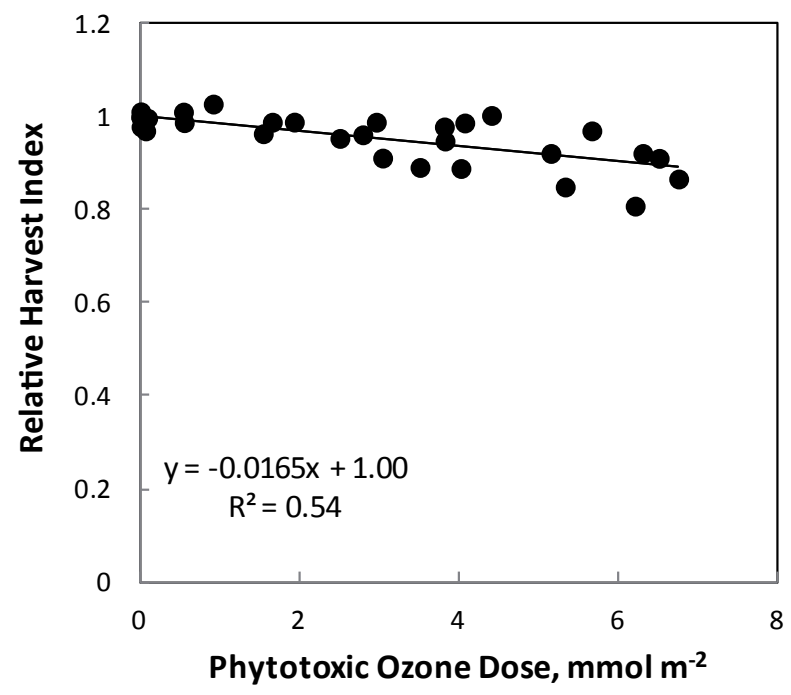

Figure 4. Relative harvest index vs. Phytotoxic Ozone Dose above a threshold of $6 \mathrm{nmol} \mathrm{m}^{-2} \mathrm{~s}^{-1}\left(\mathrm{POD}_{6}\right)$ based on 12 experiments from 3 countries (Belgium, Finland, Sweden). The relative scale is based on the assumption that there is no effect of ozone on harvest index at zero $\mathrm{POD}_{6}$ in each experiment.

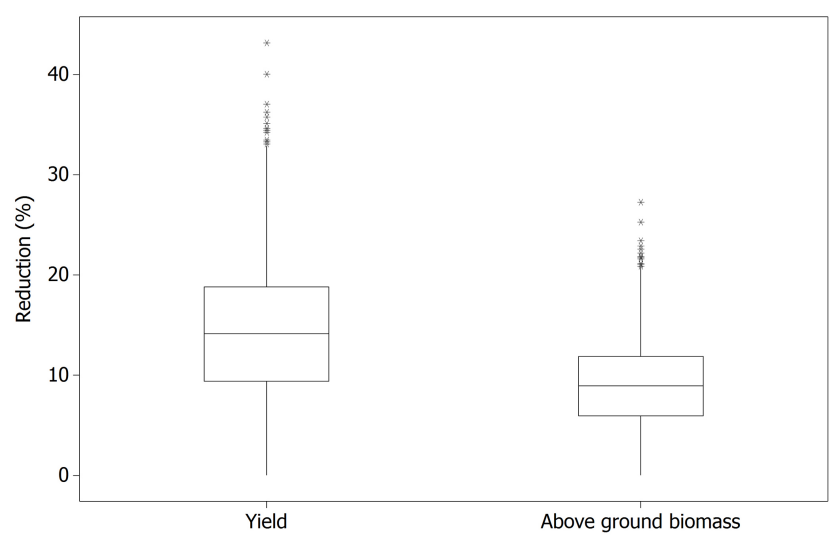

Figure 5. Estimated relative grain yield and above-ground biomass loss of wheat in Europe. The box and whisker plots are based on calculations of $\mathrm{POD}_{6}$ for all $\left(\mathrm{ca} .50 \times 50 \mathrm{~km}^{2}\right)$ grid squares from the EMEP MSC-W model in which wheat is grown. The box represents the $25-75 \%$ range of the data, whiskers show the full range of the data, and $*$ indicates outliers.

\subsection{Dose-response functions for ozone effects on $B_{A}$ and $H_{I}$ in wheat}

Figures 3 and 4 represent $\mathrm{POD}_{6}$-based response functions for the ozone effects on $B_{\mathrm{A}}$ and $H_{\mathrm{I}}$, respectively, based on the 12 experiments for which the necessary data were available. The $\mathrm{POD}_{6}$ index, which is sensitive to the ozone uptake by the plants as influenced by ozone concentrations, air humidity (vapour pressure deficit), temperature, solar radiation and phenology, has been shown to correlate strongly with ozone effects in several plants (Mills et al., 2011a). 
(a)

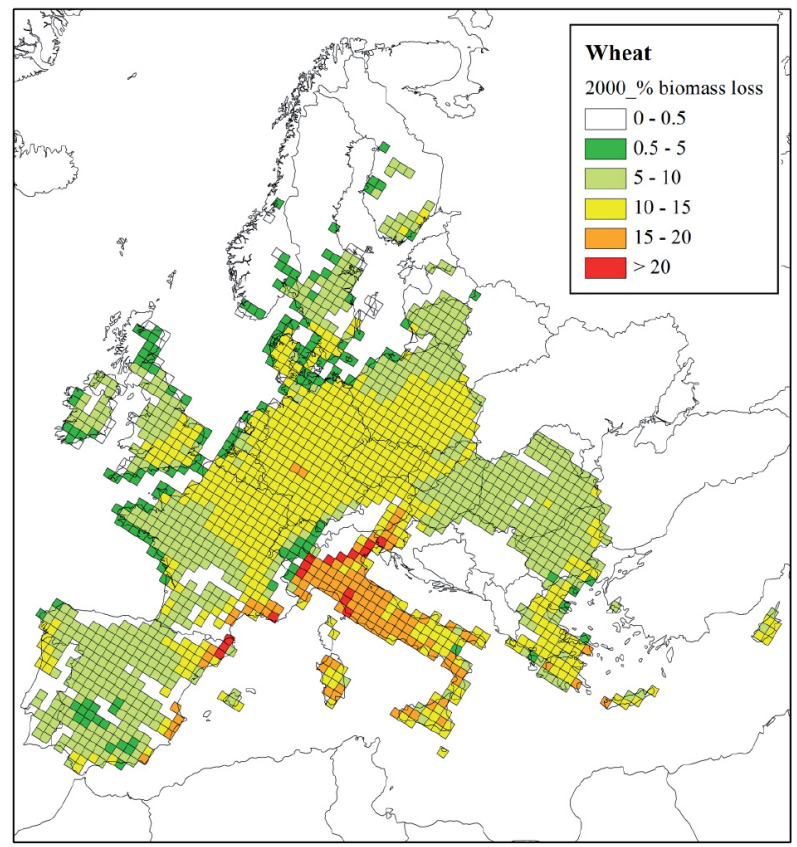

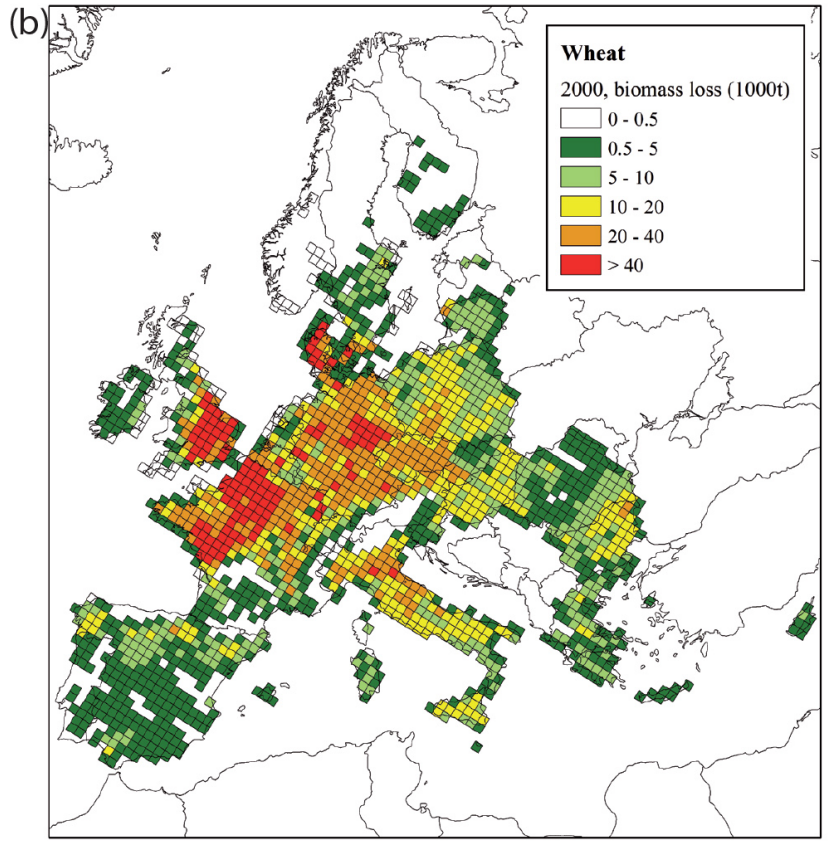

Figure 6. Geographical distribution of ozone effects on wheat biomass over Europe based on results from the EMEP MSC-W model for the year 2000: (a) percentage losses in biomass and (b), effects on total above-ground biomass per $50 \times 50 \mathrm{~km}$ grid square.

The relationships shown in Figs. 3 and 4 use the most recent calibration of the stomatal conductance model for wheat developed under the ICP Vegetation of the Convention on Long-Range Transboundary Air Pollution (LRTAP Convention, 2010). It is thus directly comparable with the response function for wheat grain yield using the stomatal conductance model published earlier (Pleijel et al., 2007; Mills et al., 2011b; Grünhage et al., 2012) and is based on a subset of the data for which both biomass and yield effects are available. $B_{\mathrm{A}}$ (Fig. 3) and $H_{\mathrm{I}}$ (Fig. 4) were both significantly and negatively related to $\mathrm{POD}_{6}$, but the negative slopes were smaller ( -0.024 for $B_{\mathrm{A}}$ and -0.017 for $H_{\mathrm{I}}$ ) compared to $Y_{\mathrm{G}}$ (-0.038; Mills et al., 2011b).

\subsection{Modelled ozone effects on $\boldsymbol{B}_{\mathrm{A}}$ and $\boldsymbol{Y}_{\mathrm{G}}$ for Europe}

With the purpose of studying the relationship between the estimates of ozone effects on wheat $Y_{\mathrm{G}}$ and $B_{\mathrm{A}}$, the EMEP model results for the year 2000 were combined with response functions for $Y_{\mathrm{G}}$ and $B_{\mathrm{A}}$. Figure 5 shows the average and variation of the estimated ozone-induced loss of wheat $B_{\mathrm{A}}$ and $Y_{\mathrm{G}}$. The comparison reflects the substantial variation in POD $_{6}$ ozone exposure over Europe and shows an average reduction of biomass loss of $9 \%$ compared to $14 \%$ for grain yield loss, suggesting a ratio of $\sim 0.64$ between the effects on $B_{\mathrm{A}}$ and $Y_{\mathrm{G}}$.

The geographical distribution over Europe of the effects on wheat biomass estimated with the EMEP model for year 2000 is presented in Fig. 6. The largest percentage effects (Fig. 6a) are indicated for parts of the Mediterranean, but also major parts of central Europe exhibit effects above $10 \%$. In peripheral parts of Europe, where wheat is still grown (i.e. not in the areas with the coldest climates), effects are mostly in the range between 5 and $10 \%$. However, when the quantity of above-ground wheat biomass per grid square was considered (Fig. 6b) the impact on above-ground biomass was highest in central and northern areas, where wheat is a dominant crop and climatic conditions are highly conducive to ozone uptake. In total, this analysis suggests that ozone pollution in 2000 accounted for over 22.2 million tonnes of lost biomass in the wheat-growing areas as shown in Fig. $6 \mathrm{~b}$. Applying (incorrectly) the grain yield response function to the biomass data instead of the biomass response function of this paper would have indicated above-ground biomass losses totalling 38.1 million tonnes (i.e. overestimating effects by 15.9 million tonnes). The median value for the above-ground biomass losses, as shown in Fig. 6b, was 7.2 thousand tonnes per grid square, whilst applying the grain loss function would have indicated a median loss of 12.2 thousand tonnes per grid square.

\section{Discussion}

By reducing plant photosynthesis and growth, elevated tropospheric ozone will result in decreased carbon storage in vegetation and thus in an indirect radiative forcing as a consequence of the $\mathrm{CO}_{2}$ that remains in the atmosphere due to impaired ecosystem carbon storage (Sitch et al., 2007; Collins et al., 2010; Ainsworth et al., 2012). However, using the loss 
in $Y_{\mathrm{G}}$ of an ozone-sensitive crop like wheat in large-scale vegetation models to represent biomass production (without considering the ozone effect on biomass partitioning) will lead to a substantial overestimation of the contribution of tropospheric ozone to this kind of indirect radiative forcing. Overestimation can be avoided by using a response function for $B_{\mathrm{A}}$ instead of $Y_{\mathrm{G}}$, such as that shown in Fig. 3, instead of response functions for $Y_{\mathrm{G}}$.

The significant negative effect of ozone on $H_{\mathrm{I}}$ can be explained by the post-anthesis (anthesis is the appearance of the anthers, i.e. start of flowering) high sensitivity to ozone in annual crops such as wheat (Pleijel et al., 1998). After anthesis plants become prone to senescence, induced for example by ozone (Grandjean and Fuhrer, 1989; Pleijel et al., 1997). This leads to a shorter period of post-anthesis grain-filling duration (Gelang et al., 2000), which results in a smaller grain biomass in relation to total biomass (i.e. lower $H_{\mathrm{I}}$ ) and thus represents a reduced efficiency in the conversion of accumulated biomass to grain. Thus it explains the reduction in average grain/seed mass, which is a typical characteristic of ozone effects on seed crops such as wheat, even at current ambient air concentrations (Pleijel, 2011). Since both $Y_{\mathrm{G}}$ and grain mass affect the economic return of the agricultural harvest, they need to be considered in any analysis of the economic loss from ozone exposure of wheat and other seed crops.

Estimates of the percent change in $B_{\mathrm{A}}$ were more than one-third lower than effects on $Y_{\mathrm{G}}$, leading to overestimations of effects on carbon storage if yield alone is the determining factor in analysis. There are of course uncertainties in extrapolating our results to all crops on a global basis, and also in calculations of $\mathrm{POD}_{6}$ itself (Tuovinen et al., 2007). Nevertheless, mean ozone effects on $B_{\mathrm{A}}$ of $9 \%$ are relatively large, and as wheat is the most important crop in Europe, and the fourth most important in the world (http://faostat.fao.org/site/339/default.asp), it is highly relevant to further investigate the extent to which ozone-induced biomass loss in wheat as well as other plants contributes to radiative forcing. Also, our results show that ground-level ozone has the potential to substantially affect the grain yield of wheat, with important consequences for human nutrition.

Although the effects showed non-negligible variation over Europe (Fig. 6), the analysis resulting from the use of the EMEP model suggests a substantial ozone effect on wheat biomass over much of the area where wheat is actually grown. The largest effects on total above-ground biomass were predicted to be in central and northern Europe, where wheat is most extensively grown and climatic conditions are highly conducive to ozone uptake. It should be kept in mind that in most cases the effects of ozone on below-ground biomass accumulation is not or incompletely known, but there is evidence to suggest that below-ground biomass in many plants, including crops, can be more strongly affected by ozone than above-ground biomass (Cooley and Manning, 1987). Thus, the full reduction of biomass accumulation may be larger than that suggested by the effects on $B_{\mathrm{A}}$, although the magnitude of the below-ground effect remains uncertain and requires further study.

The main conclusion of this study is that biomass partitioning is important to consider in crops like wheat, e.g. when assessing effects of ozone on indirect carbon sequestration. Previous studies using effects on relative grain yield loss to estimate effect on net photosynthesis from ozone are likely to have resulted in overestimates. This paper provides an alternative function based on ozone effects on biomass instead of grain/seed yield.

It should be noted that the standing biomass effects shown in Figs. 5 and 6 do not represent direct estimates of the carbon storage effect. Comprehensive understanding of carbon cycling responses depends on models which take into consideration downstream effects, such as heterotrophic respiration and soil organic matter build up/decomposition in the agroecosystems, but also the further use and longevity of agricultural products. Such an analysis is beyond the scope of this paper. However, our analysis shows the considerable difference between biomass effects and grain yield effects, which has strong implications for modelling of effects of ozone on carbon storage in agroecosystems.

Finally, apart from the consequences of the partitioning effect which is highlighted in this paper, future use of the effect of ozone on biomass to estimate the ozone effect on photosynthesis should be supported by evidence that is based on a valid assumption.

Acknowledgements. The authors wish to thank the Strategic Research Area BECC (Biodiversity and Ecosystem Services in a Changing Climate, http://www.becc.lu.se/), the EU FP7 programme ECLAIRE (Project No. 282910), EMEP under UN-ECE, and UK Defra (AQ0816) for financial support. We also thank colleagues at SEI-York for spatial crop yield data prepared under contract AQ0816.

Edited by: P. Stoy

\section{References}

Ainsworth, E. A., Yendrek, C. R., Sitch, S., Collins, W. J., and Emberson, L. D.: The effect of Tropospheric Ozone on Net Primary Productivity and Implications for Climate Change, Annu. Rev. Plant Biol., 63, 637-661, 2012.

Cooley, D. R. and Manning, W. J.: The impact of ozone on assimilate partitioning in plants: a review, Environ. Pollut., 47, 95-113, 1987.

Collins, W. J., Sitch, S., and Boucher, O.: How vegetation impacts affect climate metrics for ozone precursors, Geophys. Res., 115, D23308, doi:10.1029/2010JD014187, 2010.

Emberson, L., Ashmore, M., Simpson, D., Tuovinen, J.-P., and Cambridge, H.: Modelling and mapping ozone deposition in Europe Water Air Soil Pollut., 130, 577-582, 2001.

Evans, L. T.: Crop Evolution, Adaptation and Yield, Cambridge University Press, 1993. 
Feng, Z. and Kobayashi, K.: Assessing the impacts of current and future concentrations of surface ozone on crop yield with metaanalysis, Atmos. Environ., 43, 1510-1519, 2009.

Fuhrer, J., Egger, A., Lehnherr, B., Grandjean, A., and Tschannen, W.: Effects of ozone on the yield of spring wheat (Triticum aestivum L., cv. Albis) grown in open-top chambers, Environ. Pollut., 60, 273-289, 1989.

Fuhrer, J., Grandjean Grimm, A., Tschannen, W., and ShariatMadari, H.: The response of spring wheat (Triticum aestivum L.) to ozone at higher elevations. II. Changes in yield, yield components and grain quality in response to ozone flux, New Phytol., 121, 211-219, 1992.

Gelang, J., Pleijel, H., Sild, E., Danielsson, H., Younis, S., and Selldén, G.: Rate and duration of grain filling in relation to flag leaf senescence and grain yield in spring wheat (Triticum aestivum) exposed to different concentrations of ozone, Physiol. Plantarum., 110, 366-375, 2000.

Grandjean, A. and Fuhrer, J.: Growth and leaf senescence in spring wheat (Triticum aestivum) grown at different ozone concentrations in open-top field chambers, Physiol. Plantarum, 77, 389394, 1989.

Grünhage, L., Pleijel, H., Mills, G., Bender, J., Danielsson, H., Lehmann, Y., Castell, J. F., and Bethenod, O.: Updated stomatal flux and flux-effect models for wheat for quantifying effects of ozone on grain yield, grain mass and protein yield, Environ. Pollut., 165, 147-157, 2012.

Leisner, C. P. and Ainsworth, E. A.: Quantifying the effects of ozone on plant reproductive growth and development, Glob. Change Biol., 18, 606-616, 2012.

LRTAP Convention: edited by: Mills, G., Chapter 3 of the LRTAP Convention Manual of Methodologies for Modelling and Mapping Effects of Air Pollution, available at: http://icpvegetation. ceh.ac.uk/, 2010.

Mills, G. and Harmens, H.: Ozone pollution: A hidden threat to food security, ICP Vegetation Programme Coordination Centre, CEH Bangor, UK, ISBN: 978-1-906698-27-0, 2011.

Mills, G., Hayes, F., Simpson, D., Emberson, L., Norris, D., Harmens, H., and Büker, P.: Evidence of widespread effects of ozone on crops and (semi-)natural vegetation in Europe (1990-2006) in relation to AOT40- and flux-based risk maps, Glob. Change Biol., 17, 592-613, 2011a.

Mills, G., Pleijel, H., Braun, S., Büker, P., Bermejo, V., Calvo, E., Danielsson, H., Emberson, L., González Fernández, I., Grünhage, L., Harmens, H., Hayes, F., Karlsson, P. E., and Simpson, D.: New stomatal flux-based critical levels for ozone effects on vegetation, Atmos. Environ., 45, 5064-5068, $2011 \mathrm{~b}$.

Mortensen, L. and Engvild, K. C.: Effects of ozone on ${ }^{14} \mathrm{C}$ translocation velocity and growth of spring wheat (Triticum aestivum L.) exposed in open-top chambers, Environ. Pollut., 87, 135-140, 1995.

Mulchi, C., Rudorff, B., Lee, E., Rowland, R., and Pausch, R.: Morphological responses among crop species to full-season exposures to enhanced concentrations of atmospheric $\mathrm{CO}_{2}$ and $\mathrm{O}_{3}$, Water Air Soil Pollut., 85, 1379-1386, 1995.

Mulholland, B. J, Craigon, J., Black, C. R., Colls, J. J., Atherton, J., and Landon, G.: Growth, light interception and yield responses of spring wheat (Triticum aestivum L.) grown under elevated $\mathrm{CO}_{2}$ and $\mathrm{O}_{3}$ in open-top chambers, Glob. Change Biol., 4, 121130, 1998 .
Ojanperä, K., Pätsikkä, E., and Yläranta, T.: Effects of low ozone exposure of spring wheat on net $\mathrm{CO}_{2}$ uptake, Rubisco, leaf senescence and grain filling, New Phytol. 138, 451-460, 1998.

Piikki, K., De Temmerman, L., Ojanperä, K., Danielsson, H., and Pleijel, H.: The grain quality of spring wheat (Triticum aestivum L.) in relation to ozone uptake and carbon dioxide exposure, Eur. J. Agron., 28, 245-254, 2008.

Pleijel, H.: Reduced ozone by air filtration consistently improved grain yield in wheat, Environ. Pollut., 159, 897-902, 2011.

Pleijel, H., Skärby, L., Wallin, G., and Sellden, G.: Yield and grain quality of spring wheat (Triticum aestivum L., cv. Drabant) exposed to different concentrations of ozone, Environ. Pollut., 69, 151-168, 1991.

Pleijel, H., Skärby, L., Wallin, G., and Selldén, G.: A processoriented explanation of the non-linear relationship between grain yield of wheat and ozone exposure, New Phytol., 131, 241-246, 1995.

Pleijel, H., Ojanperä, K., Danielsson, H., Sild, E., Gelang, J., Wallin, G., Skärby. L., and Selldén, G.: Effects of ozone on leaf senescence in spring wheat - possible consequences for grain yield, Phyton.-Ann. Rei. Bot., 37, 227-232, 1997.

Pleijel, H., Danielsson, H., Gelang, J., Sild, E., and Selldén, G.: Growth stage dependence of the grain yield response to ozone in spring wheat (Triticum aestivum L.), Agr. Ecosyst. Environ., 70, 61-68, 1998.

Pleijel, H., Gelang, J., and Danielsson, H.: Effects of elevated carbon dioxide, ozone and water availability on spring wheat growth and yield, Physiol. Plantarum, 108, 61-70, 2000.

Pleijel, H., Berglen Eriksen, A., Danielsson, H., Bondesson, N., and Selldén, G.: Differential ozone sensitivity in an old and a modern Swedish wheat cultivar - grain yield and quality, leaf chlorophyll and stomatal conductance, Env. Exp. Bot. 56, 63-71, 2006.

Pleijel, H., Danielsson, H., Emberson, L., Ashmore, M., and Mills, G.: Ozone risk assessment for agricultural crops in Europe: further development of stomatal flux and flux-response relationships for European wheat and potato, Atmos. Environ., 41, 3022-3040, 2007.

Rai, R., Agrawal, M., and Agrawal, S. B.: Assessment of yield losses in tropical wheat using open top chambers, Atmos. Environ. 41, 9543-9554, 2007.

Simpson, D., Emberson, L., Ashmore, M., and Tuovinen, J.-P.: A comparison of two different approaches for mapping potential ozone damage to vegetation. A model study, Environ. Pollut., 146, 715-725, 2007.

Simpson, D., Benedictow, A., Berge, H., Bergström, R., Emberson, L. D., Fagerli, H., Flechard, C. R., Hayman, G. D., Gauss, M., Jonson, J. E., Jenkin, M. E., Nyíri, A., Richter, C., Semeena, V. S., Tsyro, S., Tuovinen, J.-P., Valdebenito, Á., and Wind, P.: The EMEP MSC-W chemical transport model - technical description, Atmos. Chem. Phys., 12, 7825-7865, doi:10.5194/acp-127825-2012, 2012.

Slaughter, L. H., Mulchi, C. L., Lee, E. H., and Tuthill, K.: Chronic ozone stress effects on yield and grain quality of soft red winter wheat, Crop Sci., 29, 1251-1255, 1989.

Sitch, S., Cox, P. M., Collins, W. J., and Huntingford, C.: Indirect forcing of climate change through ozone effects on the landcarbon sink, Nature, 448, 791-793, 2007. 
Tuovinen, J.-P., Simpson, D., Ashmore, M., Emberson, L., and Gerosa, G.: Robustness of modelled ozone exposures and doses, Environ. Pollut., 146, 578-586, 2007.
Underwood, A. J.: Experiments in ecology, Cambridge University Press, Cambridge, 1997. 